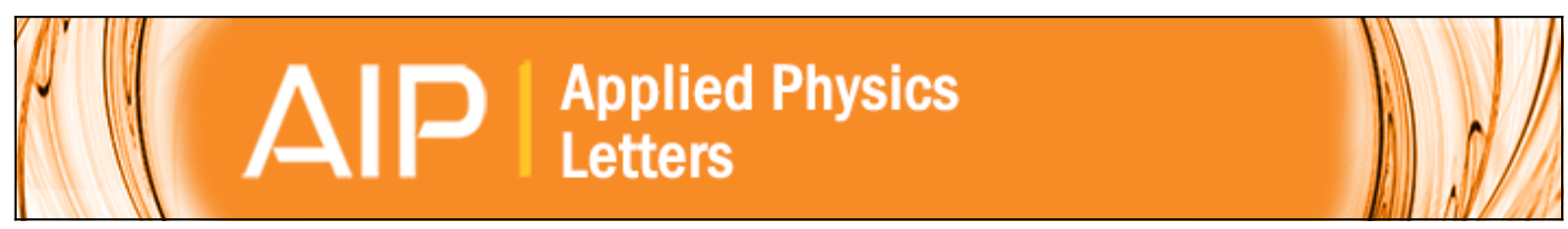

\title{
Superconducting fiber
}

D. Homa, Y. Liang, and G. Pickrell

Citation: Applied Physics Letters 103, 082601 (2013); doi: 10.1063/1.4819074

View online: http://dx.doi.org/10.1063/1.4819074

View Table of Contents: http://scitation.aip.org/content/aip/journal/apl/103/8?ver=pdfcov

Published by the AIP Publishing

\section{Articles you may be interested in}

Soliton self-frequency shift and dispersive wave in a hybrid four-hole AsSe2-As2S5 microstructured optical fiber Appl. Phys. Lett. 104, 121911 (2014); 10.1063/1.4869756

Composition dependence of the microspectroscopy of Cr ions in double-clad Cr:YAG crystal fiber J. Appl. Phys. 99, 093113 (2006); 10.1063/1.2196220

Fiber-optic evanescent field modulator using a magnetic fluid as the cladding J. Appl. Phys. 99, 093516 (2006); 10.1063/1.2195016

Transient radiation responses of silica-based optical fibers: Influence of modified chemical-vapor deposition process parameters

J. Appl. Phys. 99, 023104 (2006); 10.1063/1.2161826

Hydrogen-induced reduction of axial stress in optical fiber cores

Appl. Phys. Lett. 74, 516 (1999); 10.1063/1.123172

\section{AlP Re-register for Table of Content Alerts}




\title{
Superconducting fiber
}

\author{
D. Homa, Y. Liang, and G. Pickrell \\ Department of Materials Science and Engineering, Virginia Polytechnic Institute and State University, \\ 401 Holden Hall, Blacksburg, Virginia 24060, USA
}

(Received 9 June 2013; accepted 2 August 2013; published online 19 August 2013)

In this study, we demonstrated superconductivity in a fiber with a lead core and fused silica cladding. The fibers were fabricated via a melt-draw technique and maintained overall diameters ranging from $200-900 \mu \mathrm{m}$ and core diameters of $100-800 \mu \mathrm{m}$. Superconductivity of this fiber design was validated via the traditional four probe test method in a bath of liquid helium at temperatures on the order of $4 \mathrm{~K}$. The superconducting fiber paves the way for applications in power transmission, magnetic sensing, and fundamental studies in the fields of electromagnetism. (C) 2013 AIP Publishing LLC. [http://dx.doi.org/10.1063/1.4819074]

Since its discovery by Dutch physicist Heike Kamerlingh Onnes in 1911, superconductivity has fascinated the scientific community. ${ }^{1}$ Significant effort has been directed on the fundamental understanding of the phenomena, as well as the applied research in the power transmission and sensing applications. ${ }^{2-5}$ More recently, progress has been made in the development of high quality, long length, high current coated high temperature superconductors. ${ }^{6-9}$ The cable structures, though, are often very exotic and require complicated manufacturing processes. ${ }^{10-12}$ Simple and cost effective superconductor cable designs and fabrication processes are required to enable wide implementation. However, not much attention has been paid to processing schemes or possible adaptations to more mature processes that can be readily scalable.

The fiber optic revolution in telecommunication and sensing applications was, in part, facilitated by economically robust and standardized designs. ${ }^{13}$ In parallel, optical fiber manufacturing techniques evolved to a level of worldwide acceptance with the increased demand. ${ }^{14}$ These synthesis routes and designs can be readily adapted to other materials such as metals, semiconductors, and ceramics. ${ }^{15-20}$ To date, superconductivity has yet to be demonstrated in a fiber structure.

The basic optical fiber designs are excellent templates for the development of superconductors. For example, the superconducting core can be surrounded by an insulating material such as fused silica to allow for efficient cooling. The holes in random and ordered hole fibers allow for cryogenic cooling with liquid nitrogen and/or helium. ${ }^{21-23}$ The supporting methodologies, such as splicing and cable designs, in place for optical fibers can also be readily adapted to superconductor core fiber designs. Furthermore, the integration of superconductivity and optical waveguides has been of large interest for ultrasensitive, ultra-fast, and ultralow noise light detectors, but to date has only been evaluated experimentally. ${ }^{24,25}$ The development of a superconducting fiber will not only provide the impetus for scientific discovery but will also provide for the potential to cost effectively integrate various technologies in one simple component.

In this letter, we demonstrate a Type I superconducting fiber, as seen in Figure 1. The lead core of these types of fibers exhibited zero resistance at temperatures of approximately $7.2 \mathrm{~K}$.

The superconducting core fibers were prepared by the melt-draw technique on a traditional glass working lathe, as seen in Figure $2 .{ }^{26}$ First, a fused silica substrate tube (GE214, O.D. $=8 \mathrm{~mm}$, I.D. $=3 \mathrm{~mm}$ ) was fused to a processing tube $(\mathrm{GE} 214$, O.D. $=12.75 \mathrm{~mm}$, I.D. $=10.5 \mathrm{~mm})$. Lead wire (Alfa Aesar, approximately 99.9\% (metals basis) with a diameter of $2 \mathrm{~mm}$ was placed in the processing tube and melted via an oxy-hydrogen flame at a temperature of approximately $300^{\circ} \mathrm{C}$ ). A smaller diameter fused silica rod (GE214, $8 \mathrm{~mm}$ ) was used to push the lead melt into the substrate tube forming a preform with a lead core. Finally, the preform was drawn into a fiber via a technique similar to the Taylor process. ${ }^{27,28}$

To date, all the fibers were fabricated on a glass working lathe, Litton Model HSJ143. Subsequently, the maximum achievable fiber lengths were limited by the working distance, approximately $120 \mathrm{~cm}$, between the chuck faces, as well as the preform length, and drawing rod at the tailstock end, as seen in Figure 2. Fiber diameters in the range of $100-900 \mu \mathrm{m}$ were routinely fabricated to maximum lengths of $120 \mathrm{~cm}$. Fiberization via the glass working lathe allows

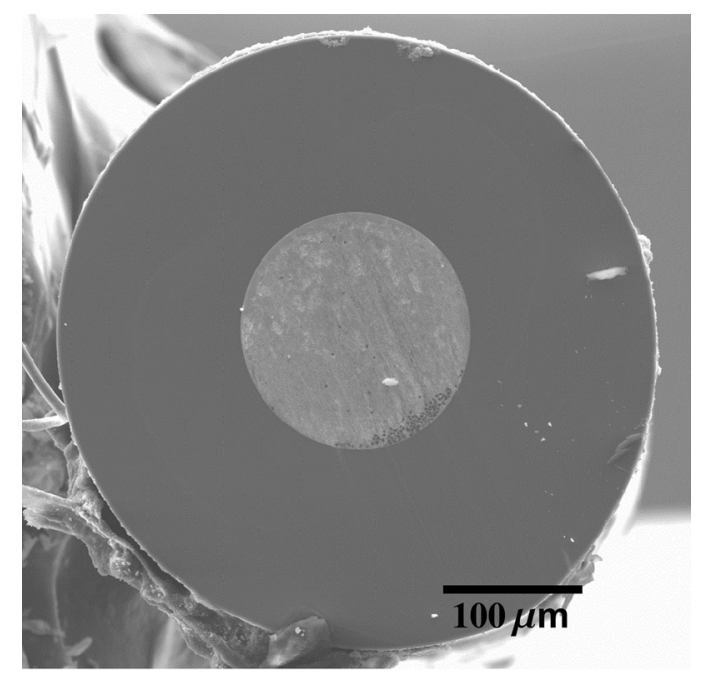

FIG. 1. SEM image of a superconducting fiber endface with a $165 \mu \mathrm{m}$ lead core and overall fused silica cladding diameter of $430 \mu \mathrm{m}$. 
for "real-time" qualitative and visual analysis of the basic material interactions and compatibilities, as well preliminary determination of process feasibility. The fundamental technique is based on the Taylor and Taylor-Ulitovsky methods which are typically performed on a more traditional draw tower structure, and have been thoroughly studied and implemented commercially to manufacture fiber lengths on the order of kilometers. ${ }^{29-31}$

Polished fiber cross sections were characterized with a scanning electron microscope (SEM, LEO 1550). The microstructure of a selected superconducting fiber cross section can be seen, again, in Figure 1. The fused silica cladding maintained a clad diameter of approximately $430 \mu \mathrm{m}$ and lead core diameter of $165 \mu \mathrm{m}$.

Energy dispersive spectroscopy (EDS) chemical composition and mapping were performed with an attached IXRF System, Inc., Iridium Microanalysis System at an accelerating voltage of $20.0 \mathrm{kV}$. The EDS mapping images at the core-cladding interface can be seen in Figure 3. A distinct transition between the cladding, $\mathrm{SiO}_{2}$, and the core, $\mathrm{Pb}$, exists at the interface; no apparent cross-diffusion at the boundary is apparent. $\mathrm{Pb}$ and $\mathrm{Si}$ show no diffusion behavior across the interface line, which is also confirmed by EDS chemical composition spectra. Minimal levels of $\mathrm{PbO}$ were noted in the core, but further analysis is required to verify the source of oxygen, i.e., environmental sources during synthesis, diffusion from the cladding, and/or measurement artifact.

The superconductivity of the lead core fibers was verified via the four-probe test method. ${ }^{32}$ In order to connect the probes to the lead core, the fused silica cladding was removed mechanically or by etching in a hydrofluoric acid solution for a pre-determined period of time. Liquid helium was used for the lead core fiber, because the critical temperature is approximately $7.2 \mathrm{~K}$, and the boiling point of liquid helium is $4 \mathrm{~K}$.

The four point probe test method was performed to accurately measure the voltage drop across the lead core. The effects of contact resistance are eliminated via the four probe test method. As seen in Figure 4, the two outer probes provide a constant electrical current, while the inner probes are used to monitor the voltage. Resistance to the flow of electrical current will produce a voltage drop measured between the

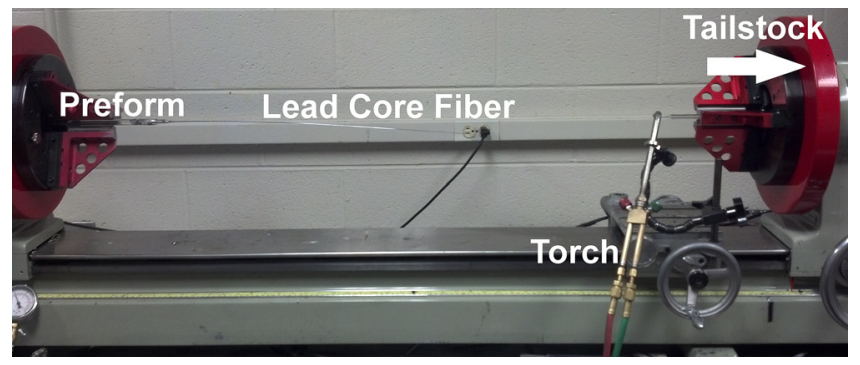

FIG. 2. The custom fiber drawing system utilized to fabricate the lead core superconducting fibers. The glass working lathe (Litton Lathe Model HSJ143) consists of traversing hand torch and tailstock chuck, as well as a headstock chuck for holding the preform. The ends of the preform are held in the rotating chucks, and heated to the softening point via the hydrogen/ oxygen torch. The preform is then pulled into a fiber by rapidly traversing the tailstock downstream. The approximate maximum fiber length of $120 \mathrm{~cm}$ is limited by working distance between the chuck faces.

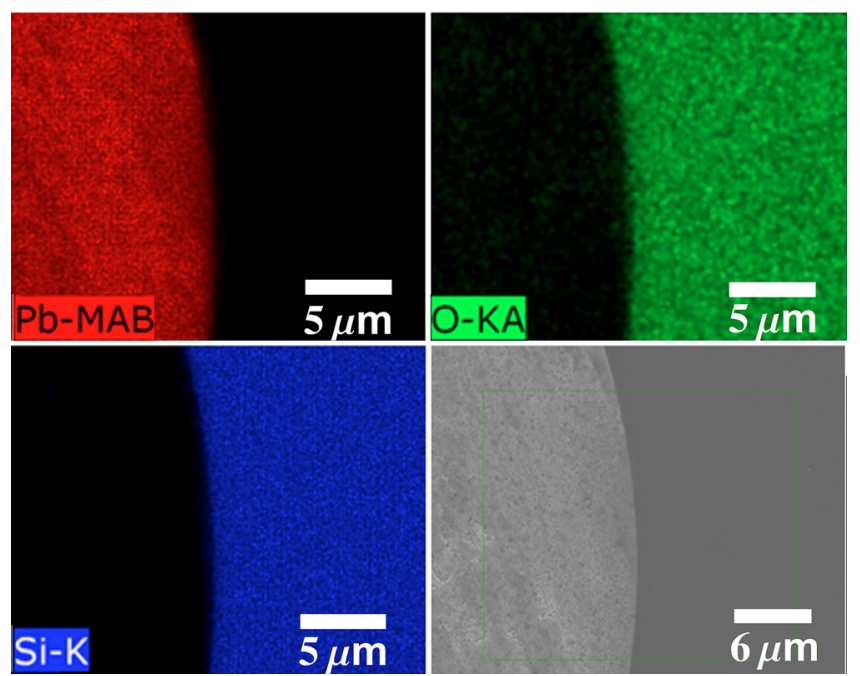

FIG. 3. X-ray dot mapping of oxygen, lead, and silicon at the lead corefused silica cladding interface. There is limited to no diffusion of the lead, $\mathrm{Pb}$, into the cladding. Conversely, there is limited to no diffusion of the silicon, $\mathrm{Si}$, into the core. Limited oxygen diffusion from the cladding into the core can be seen in the top right dot map image.

two voltage probes. Conversely, a superconductor will exhibit no voltage drop below the critical temperature.

A HP Hewlett Packard Agilent, 6633A System was utilized as the direct current supply and ammeter. An Agilent, 34405A, $51 / 2$ Digit Multi-meter was connected to the "voltage probes" to accurately measure the voltage drop. The current test set-up utilized in these experiments did not allow for precise temperature measurements due to the inherent temperature measurement errors of the Type T and E thermocouples at liquid helium temperatures. Furthermore, the use of a low form shallow glass dewar flask, Fisherbrand $($ ) $350 \mathrm{ml}$ (ID $=80 \mathrm{~mm}$ ), limited the maximum testable fiber length and wire lengths to approximately $50 \mathrm{~mm}$.

A baseline measurement was performed with the commercially available lead wire (diameter $=2 \mathrm{~mm}$ ) in a liquid helium bath to confirm the validity of the test setup. Superconducting fibers with core diameters of approximately

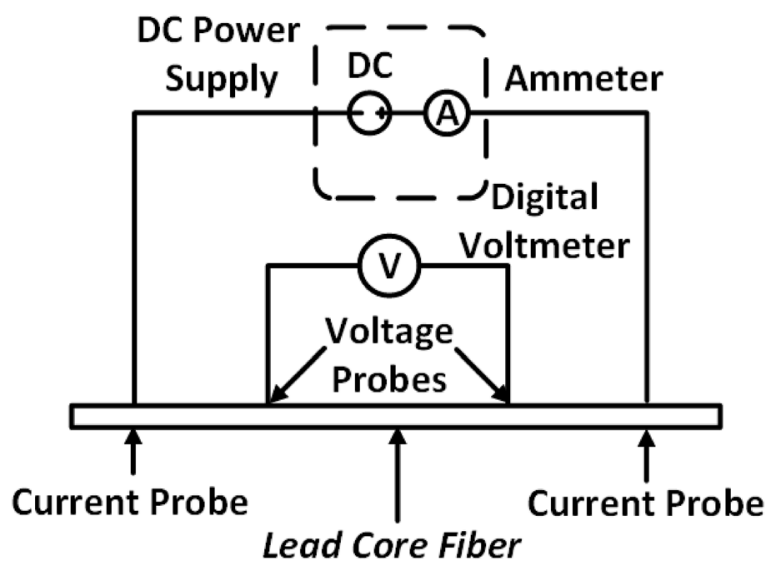

FIG. 4. Schematic of the Four Point Probe test setup. Three samples were tested: (1) "as received" commercial lead wire, (2) lead core superconducting fiber with a fused silica clad, and (3) lead superconducting core fiber with the clad removed. The sample length of $5 \mathrm{~mm}$ was limited by the inner diameter of Fisherbrand ${ }^{\circledR}$ low form shallow glass dewar flask $(80 \mathrm{~mm}$ $\times 75 \mathrm{~mm}$ ). A voltage drop of approximately $1.1 \mathrm{mV}$ at $25^{\circ} \mathrm{C}$ was set for each sample by adjusting the current. 
$800 \mu \mathrm{m}$ were tested with and without the fused silica cladding. As seen in Figure 5, the resistance of the commercial lead wire disappeared at temperatures on the order of $7.2 \mathrm{~K}$. The superconducting lead core fibers appeared to demonstrate a slightly lower $T_{c}$ on the order of $4-6 \mathrm{~K}$. The slight decrease in the critical temperature could be attributed to impurities and/or defects incorporated during fiber processing, both of which can be reduced or eliminated with commercially available process control systems and methodologies. Measurement errors were also possible due to thermal electromotive forces, external electromagnetic radiation, Faraday currents, and the degradation of the electrical contacts, as well as basic errors in the experimental set-up. ${ }^{33,34}$ In an effort to isolate any possible temperature measurement artifacts, the resistance of all the samples was also evaluated as a function of time upon natural warming to room temperature. As seen in Figure 6, the lead core fibers and commercial lead wire exhibit similar transitions to superconductivity and resistance-time profiles. The critical temperature has been verified and extensively studied in the literature and is generally accepted as approximately $7.2 \mathrm{~K}$, which is in good agreement with the measurements in this study. ${ }^{1}$

In all tests, the voltage drop across the voltage probes was held constant at approximately $1.1 \mathrm{mV}$ at room temperature. The following equation is utilized to determine the required current:

$$
R=\frac{V}{I}=\rho \frac{I}{A},
$$

where $R$ is the resistance, $V$ is the voltage, $I$ is the current, $\rho$ is the conductivity, and $A$ is area of sample cross section. Since the lead core had a smaller cross sectional area than the lead wire, the resistance was larger. Thus, a smaller current was required for the lead core to produce the same room temperature voltage drop of approximately $1.1 \mathrm{mV}$. It is

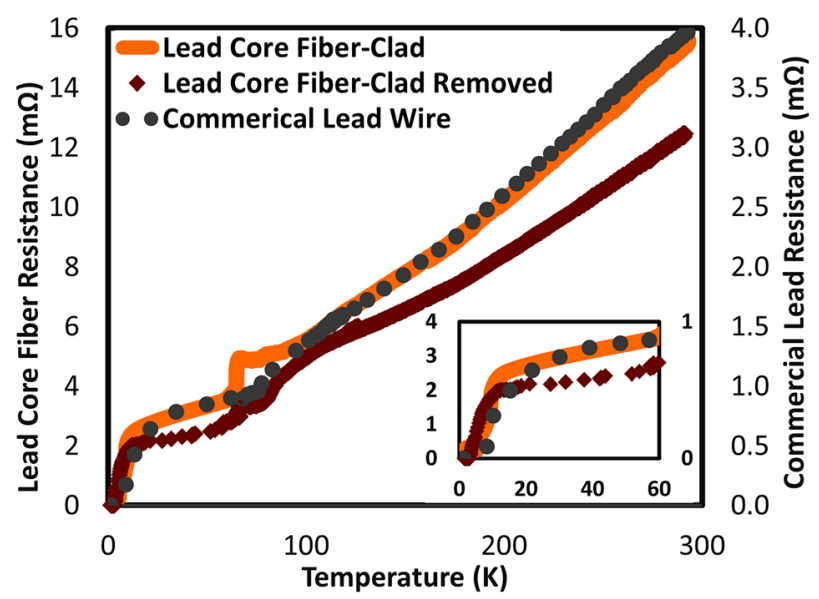

FIG. 5. Electrical resistance as a function of temperature upon full immersion in liquid helium for (a) commercial lead wire baseline sample, (b) lead core superconducting fiber with the fused silica clad, and (c) lead core superconducting fiber with the fused silica clad removed prior to testing. The primary vertical axis is the resistance of the lead core samples and the secondary vertical axis is the resistance of the commercial lead wire. A graph in the temperature range of the superconducting transition can also be seen in the bottom right corner of the graph. All samples maintain a critical temperature of approximately $4-8 \mathrm{~K}$.

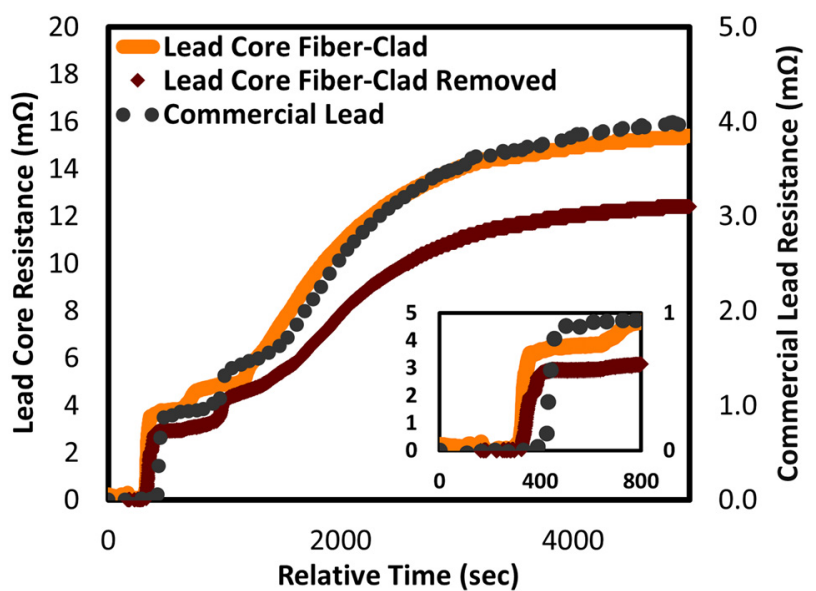

FIG. 6. Electrical resistance measurements as a relative function of time upon full immersion in liquid helium for (a) commercial lead wire baseline sample, (b) lead core superconducting fiber with the fused silica clad, and (c) lead core superconducting fiber with the fused silica clad removed prior to testing. The primary vertical axis is the resistance of the lead core samples and the secondary vertical axis is the resistance of the commercial lead wire. A graph in the range of the superconducting transition can also be seen in the bottom right corner of the graph. All samples demonstrate a similar transition to superconductivity and resistance-time profile upon warming to room temperature.

evident that both samples demonstrate superconductivity at liquid helium temperatures of approximately $4 \mathrm{~K}$.

The demonstration of a superconducting fiber is the first step in the development of truly efficient and cost effective superconducting cables. These results are only a prelude to the development of high temperature superconducting fibers with core materials such as $\mathrm{YBa}_{2} \mathrm{Cu}_{3} \mathrm{O}_{7}$ and efficient cryogenic cooling schemes based on ordered hole and random hole fiber structures. Furthermore, these results are very promising for the potential realization of compact and extremely sensitive fiber optic magnetic sensors.

The authors would like to acknowledge Dr. Gurbinder, Dr. Heremans, and Yao Zhang for their patience and invaluable assistance with our experimentation.

${ }^{1}$ H. K. Onnes, Akad. van Wet. 14(113), 818 (1911).

${ }^{2}$ M. Chen, L. Donzel, M. Lakner, and W. Paul, J. Eur. Ceram. Soc. 24(6), 1815 (2004).

${ }^{3}$ Z. Lian, Z. Pingxiang, J. Ping, W. Keguang, W. Jingrong, and W. Xiaozu, Supercond. Sci. Technol. 3(10), 490 (1990).

${ }^{4}$ H. Nojima, S. Tsuchimoto, and S. Kataoka, Jpn. J. Appl. Phys., Part 127 , 746 (1988).

${ }^{5}$ M. W. Rupich, X. Li, C. Thieme, S. Sathyamurthy, S. Fleshler, D. Tucker, E. Thompson, J. Schreiber, J. Lynch, and D. Buczek, Supercond. Sci. Technol. 23(1), 014015 (2010).

${ }^{6}$ J. Kawano, A. Tsukamoto, S. Adachi, Y. Oshikubo, T. Hato, K. Tanabe, and T. Okamura, Phys. Procedia 27, 336 (2012).

${ }^{7}$ A. P. Malozemoff, Annu. Rev. Mater. Res. 42, 373 (2012).

${ }^{8}$ D. Larbalestier, A. Gurevich, D. M. Feldmann, and A. Polyanskii, Nature 414(6861), 368 (2001).

${ }^{9}$ A. Malozemoff, S. Fleshler, M. Rupich, C. Thieme, X. Li, W. Zhang, A. Otto, J. Maguire, D. Folts, and J. Yuan, Supercond. Sci. Technol. 21(3), 034005 (2008).

${ }^{10}$ J. MacManus-Driscoll, S. Harrington, J. Durrell, G. Ercolano, H. Wang, J. Lee, C. Tsai, B. Maiorov, A. Kursumovic, and S. Wimbush, Supercond. Sci. Technol. 23(3), 034009 (2010).

${ }^{11}$ A. Ishiyama, T. Iwata, H. Ueda, S. Mukoyama, and Y. Shiohara, IEEE Trans. Appl. Supercond. 17(2), 1672-1675 (2007).

${ }^{12}$ N. Amemiya, J. Zhenan, M. Nakahata, M. Yagi, S. Mukoyama, N. Kashima, S. Nagaya, and Y. Shiohara, IEEE Trans. Appl. Supercond. 17(2), 1712-1717 (2007). 
${ }^{13} \mathrm{H}$. Murata, Handbook of Optical Fibers and Cables (CRC Press, New York, 1996).

${ }^{14}$ J. M. Senior and M. Y. Jamro, Optical Fiber Communications: Principles and Practice (Pearson Education, Harlow, 2009).

${ }^{15}$ B. Scott, K. Wang, A. Floyd, and G. Pickrell, "P-Type Silicon Optical Fiber," in Advances in Synthesis, Processing, and Applications of Nanostructures: Ceramic Transactions, Volume 238, edited by K. Lu, N. J. Manjooran, R.-i. Murakami, and G. Pickrell (John Wiley \& Sons, Inc., Hoboken, NJ, 2012), pp. 103-107.

${ }^{16}$ B. L. Scott, K. Wang, and G. Pickrell, IEEE Photonics Technol. Lett. 21(24), 1798 (2009).

${ }^{17}$ B. L. Scott and G. R. Pickrell, J. Cryst. Growth 371, 134-141 (2013).

${ }^{18}$ J. Ballato, T. Hawkins, P. Foy, C. McMillen, L. Burka, J. Reppert, R. Podila, A. Rao, and R. R. Rice, Opt. Express 18(5), 4972 (2010).

${ }^{19}$ B. Samson, L. Pinckney, J. Wang, G. Beall, and N. Borrelli, Opt. Lett. 27(15), 1309 (2002).

${ }^{20} \mathrm{~J}$. Ballato, T. Hawkins, P. Foy, B. Yazgan-Kokuoz, R. Stolen, C. McMillen, N. K. Hon, B. Jalali, and R. Rice, Opt. Express 17(10), 8029 (2009).

${ }^{21}$ D. Kominsky, G. Pickrell, and R. Stolen, Opt. Lett. 28(16), 1409 (2003).
${ }^{22}$ H. Qu and M. Skorobogatiy, Appl. Phys. Lett. 98(20), 201114 (2011).

${ }^{23}$ T. Masuda, T. Kato, H. Yumura, M. Watanabe, Y. Ashibe, K. Ohkura, C. Suzawa, M. Hirose, S. Isojima, and K. Matsuo, Physica C 378, 1174 (2002).

${ }^{24}$ G. R. Pickrell and E. Smirnova, Proceedings of the IEEE Sensors 2005 Conference (The Printing House, Inc, 2005), pp. 731-734.

${ }^{25}$ B. G. Ghamsari and A. H. Majedi, IEEE Trans. Appl. Supercond. 17(2), 590-593 (2007).

${ }^{26}$ B. Scott, K. Wang, V. Caluori, and G. Pickrell, Opt. Eng. 48(10), 100501 (2009).

${ }^{27}$ W. Grodkiewicz, Mater. Res. Bull. 10(10), 1085 (1975).

${ }^{28}$ G. Taylor, Phys. Rev. 23(5), 655 (1924).

${ }^{29}$ I. Donald and B. Metcalfe, J. Mater. Sci. 31(5), 1139 (1996).

${ }^{30}$ G. Pardoe, E. Butler, and D. Gelder, J. Mater. Sci. 13(4), 786-790 (1978).

${ }^{31}$ I. Butler, W. Kurz, J. Gillot, and B. Lux, Fibre Sci. Technol. 5(4), 243 (1972).

${ }^{32}$ J. Nagamatsu, N. Nakagawa, T. Muranaka, Y. Zenitani, and J. Akimitsu, Nature 410(6824), 63 (2001).

${ }^{33}$ J. Nicol, S. Shapiro, and P. H. Smith, Phys. Rev. Lett. 5(10), 461 (1960).

${ }^{34}$ V. Vazquez, N. Pérez-Amaro, and A. Canizo-Cabrera, Rev. Sci. Instrum. 72(8), 3332-3339 (2001). 